coloration with noradrenaline, but a very weak one with adrenaline. It sometimes affords useful confirmation for the former if interfering amino-acids are not present.

So far, no second solvent has been found in addition to phenol that will separate the adrenalines. Very little movement occurred in $n$-butanol and none in collidine, amylacetate or butyric acid. All runs have been for approximately twenty hours at room temperature, and the $R_{F}$ values observed were as follows :

Noradrenaline
'Dopa'
3,4-Dihydroxytyramine
Corbasil
Adrenaline
N-methylcorbasil
Epinine
Methyladrenaline
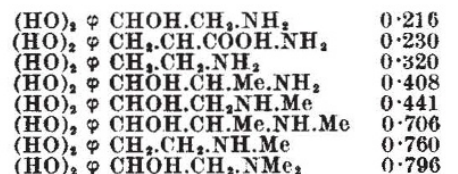

It will be seen that the movement of these substances in phenol is determined mainly by the terminal amine group and that the $R_{F}$ increases as this is methylated. An ideal separation is consequently achieved between the three adrenalines. Taking the list as a whole, satisfactory separation in a mixture cannot be guaranteed if the difference of $R_{F}$ values falls much below $0 \cdot 1$. The confusion most likely to matter in tissue extracts is that between noradrenaline and 'Dopa'. This is easily resolved by the enzyme test, because of the black colour given by 'Dopa'. Adrenaline can be distinguished from corbasil with a similar $R_{F}$ by the much greater stability of adrenochrome over the corresponding corbasil derivative in the enzyme tests.

These methods have been successfully applied to the demonstration of noradrenaline and adrenaline in tissue extracts. I am indebted to Dr. H. Blaschko for samples of most of the compounds used.

\author{
Oxford Medicinal Plants Scheme, \\ Department of Botany, \\ Oxford. \\ Consilen, R., Gordon, A. H., and Martin, A. J. P., Biochem. J., 38, \\ 224 (1944).
}

W. O. JAMES

\section{Association of Xanthine Oxidase with Virus Multiplication}

IT has previously been reported that the xanthine oxidase content of mouse brain is markedly increased during infection with yellow fever and other viruses ${ }^{\mathbf{1 , 2}}$, and evidence was adduced which suggested that this rise of enzyme activity was not fortuitous but was causally related to the growth of virus in the tissue. The possibility of the virus particles themselves having xanthine oxidase activity was excluded by the demonstrable lack of parallelism between enzyme activity and the amount of virus in the brain. Recent work reported here shows that the extra enzyme is not obtained from other parts of the body, and demonstrates that synthesis of xanthine oxidase takes place during virus infection.

Fertile eggs at the ninth day of incubation were inoculated with the $17 \mathrm{D}$ strain of yellow fever virus by the allantoic route, and were then incubated for a further period. In a preliminary Burvey of the enzyme activity of the various tissues of both normal and virus-infected eggs, it was found that xanthine oxidase was present only in the chorioallantois and

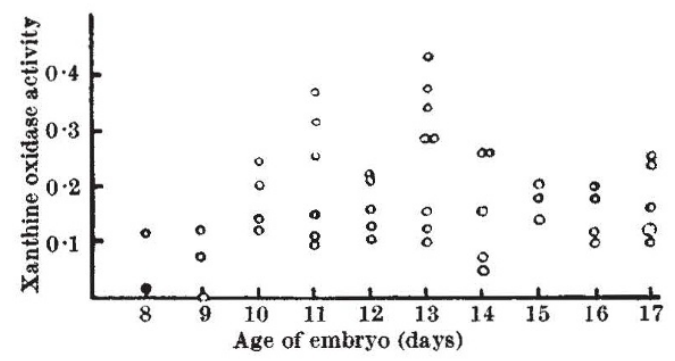

NORMAL EMBRYOS ; , EMBRYOS INFECTED WITH $17 \mathrm{D}$ STRAIN OF YELLOW FEVER VIRUS

the embryo. In all subsequent experiments the embryo and membrane were ground up together with twice the weight of water and centrifuged, and the supernatant fluid was tested for xanthine oxidase activity by the Thunberg technique. The enzyme activity of the combined tissue extract was expressed in arbitrary figures per unit weight of tissue. The results are shown in the accompanying graph. The values for normal embryos remain fairly constant throughout the period of incubation investigated; since the weight of the embryo increases from 1 to 20 gm. over this period, a continual synthesis of xanthine oxidase must be taking place of sufficient extent to maintain a uniform value per unit weight of tissue. The values for embryos infected with virus are in nearly all cases considerably higher than normal, the increase being particularly noticeable on the thirteenth day; between the thirteenth and eighteenth days the activity falls towards the normal level. Since these determinations were all made upon the embryo plus the chorioallantoic membrane, which together represent the only available source of xanthine oxidase, it is evident that the enzyme content of the whole egg is increased in response to the virus infection, and that the possibility of enzyme accumulating in infected tissues from depots elsewhere can be excluded. In addition to the synthesis of xanthine oxidase which is taking place in the normal embryo, there is thus an additional synthesis brought about by the presence of the virus, and it is suggested that this extra amount of enzyme is required for virus metabolism.

There are certain points to be noted in comparing these results with those already reported for mouse encephalitis. (1) In the chick embryo there is very little cellular response to the presence of the virus, so that the rise of enzyme activity is not likely to be due to the presence of a round-cell infiltration. (2) The maximum enzyme activity $(0.44)$ is lower than that found in mouse brain $(1 \cdot 6)$, which may be related to the lower virus titre $\left(10^{5}\right.$ in the embryo and $10^{7}$ in the mouse brain). (3) The virus titre and enzyme activity both fall from the thirteenth day onwards, and a similar fall of enzyme activity is seen in mouse encephalitis after the onset of symptoms and attainment of maximum virus titre; these facts suggest that enzyme synthesis is connected with the active proliferation of virus and occurs only during this phase.

\section{J. BAUER}

Wellcome Laboratories of Tropical Medicine, 183-193 Euston Road, London, N.W.1. Feb. 2 .

'Bauer, D. J., Nature, 159, 438 (1947).

' Bauer, D. J., Brit. J. Exp. Path., 28, 440 (1947). 